\title{
Más allá de los límites de la ideología: subjetividad y deseo
}

\author{
Beyond the limits of ideology: subjectivity and desire
}

\author{
Carlos Arrieta-Salas ${ }^{1}$ \\ Manuel Martínez-Herrera ${ }^{2}$
}

\begin{abstract}
RESUMEN
En el presente artículo se establece un vínculo entre ideología y constitución de la subjetividad, en función de la estructura social, lo simbólico, lo subjetivo y lo inconsciente como partes integrales de la realidad humana. Se impone aquí, una mirada más allá del ejercicio del poder -consustancial a los dominios ideológicos- que clásicamente ha sido estudiado por las ciencias sociales y particularmente por la sociología. La ideología es interpelada en este trabajo, a partir de la dimensión del deseo, el cual emerge en el lugar donde se fisura la estructura social y se quiebra su tiranía normativa en razón de su incapacidad de dar respuesta a una demanda subjetiva-instintiva imposible. Se propone dicha carencia perenne, como el origen del movimiento y del cambio social. Se plantea que las ideologías devienen como una suerte de formación de compromiso entre un deseo innombrado y la imposibilidad de su realización, a manera de un cumplimiento sustitutivo que siempre queda en deuda.
\end{abstract}

Palabras clave: Ideología, subjetividad, poder, fisura estructural, psicoanálisis.

\begin{abstract}
The present article establishes a link between ideology and the constitution of subjectivity, in terms of social structure, symbolic, subjective and unconscious as integral parts of reality. Here, a look beyond the exercise of power - consubstantial to the ideological domains - has traditionally been studied by the social sciences and particularly by this work sociology. Ideology is challenged in this work from the dimension of desire, from its the dimension of desire, which emerges in the place where the social structure fissures and normative tyranny breaks as a function of the inability to respond to an impossible subjective demand. Such perennial absence is proposed as the origin of the movement and of social change. It is argued that ideologies become a kind of commitment formation between an unnamed desire and the impossibility of its realization, in the form of a substitute fulfillment that always remains in debt.
\end{abstract}

Key Words: Ideology, subjectivity, power, structural fissure, psychoanalysis.

1 Universidad de Costa Rica. Doctor. Docente Escuela de Psicología. Costa Rica.

Correo electrónico: CARLOS.ARRIETA@ucr.ac.cr

2 Universidad de Costa Rica. Doctor. Decano Facultad de Ciencias Sociales. Costa Rica.

Correo electrónico: manuel.martinez@ucr.ac.cr

Recepción: 13/9/2918 Aceptación: 10/10/2018.

c) (i) (2)

Esta obra está bajo una licencia de Creative Commons Reconocimiento-NoComercial-CompartirIgual 4.0 Internacional. 
"Todas las ideologías se vinculan con un núcleo de goce”. (Žižek, 2010, p. 59)

\section{Subjetividad e ideología}

En las monarquías absolutas la voluntad omnímoda del soberano era clara y reconocible, de manera tal que se podían dirigir hacia ellas odios y lealtades. En las sociedades contemporáneas el poder se vuelve opaco tras una maraña burocrática y legal, al punto que no se reconoce en su integridad ni unidad de propósito, siendo su única característica visible el anonimato; ajeno e insensible de paso a las necesidades del individuo. Esta dinámica hace que cada vez cueste más concebir la dominación como parte de un esfuerzo de subyugación articulado y concatenado, lo cual atomiza las reivindicaciones sociales que se desarticulan producto de la fragmentación que dificulta inferir el carácter orgánico y la verdadera naturaleza del poder. De esta manera, se obvian los intereses y contradicciones sociales que se disfrazan con el ropaje de las ideologías inclusivas y universales de distinto signo. Este es el verdadero valor instrumental que cumplen las ideologías tributarias del poder.

En la modernidad tardía, con la declinación del padre edípico heredero del padre totémico (Freud, 1913/2012; Mitscherlich, 1965; Lasch, 1996) el control, basado en la autoridad, la coerción y la culpa, pierde efectividad por lo que se impone una nueva racionalidad basada en una autonomía individual protegida por derechos universales que, en todo caso, no garantizan ni la equidad ni la libertad efectivas.

La universalidad que caracteriza a la globalización es una universalidad vacía, donde los individuos son despojados de sus legítimos deseos siendo estandarizados y uniformados. De ésta manera, los anhelos individuales son también globalizados y se imponen determinadas formas de pensar, ser y sentir que se asumen como propias, cuando en realidad están predeterminadas, y las "decisiones personales" no son otra cosa más que parte de un discreto abanico de posibilidades dentro de un marco dado por el propio sistema. Las resistencias y sus lógicas contestatarias son un discurso acerca del discurso dominante, al cual 
interpelan a partir de los principios y preceptos de éste, sin que esto signifique, necesariamente, una ruptura radical con el mismo. De hecho, los movimientos de resistencia suelen enfatizar sus argumentos en la defensa de los derechos adquiridos que le son vulnerados. Los discursos alternativos son asimilados por parte de la oficialidad restándole su capacidad subversiva y volviéndolos, en muchos casos, inocuos.

Ciertamente la modernidad tardía trae consigo también una apertura de horizontes que posibilita la inclusión de la diversidad, eso sí, siempre dentro del marco y límites del libre flujo de capital que deviene como la última frontera, y punto de fractura a partir del cual se rompe todo supuesto consenso y tolerancia. Las posibilidades contemporáneas de elección se encuentran mediatizadas y normalizadas, aunque se camuflen con el ropaje de "lo diverso". El sistema, en su enorme maleabilidad posee la capacidad de incorporar, incluso, las demandas subversivas sin necesariamente mutar su naturaleza. El costo de la inclusión es la aceptación a-crítica de los dictados del sistema, a partir de los grados de libertad impuestos. Acudimos a la bancarrota de las utopías, a la época de las redes de significación preestablecidas y al mundo del cibersalvajismo del cual nos hablara Quirce (2014).

Las realidades simbólicas, tributarias de determinadas prácticas sociales, aparecen bajo un halo de obviedad y sentido común en el que se prescinde de todo análisis crítico y se colocan -sospechosamente- fuera de toda sospecha, al ser naturalizadas. Las prácticas sociales y las relaciones de poder que las atraviesan, configuran la realidad circundante del sujeto y los modos de interacción social, lo cual se asume como un orden dado, como una realidad establecida que dicta y determina las formas de convivencia y organización social, a partir de lo cual se organiza la constitución psíquica del sujeto.

Las relaciones sociales son incorporadas por el sujeto teniendo la fantasía de que el proceso transcurre de forma natural, voluntaria y racionalmente; de la misma manera que se tiene la convicción de que nuestras creencias y pensamientos son propios, sin darnos cuenta de que son impuestos, la mayoría de las veces, al margen de nuestra voluntad y de nuestra conciencia (Martínez, 2007) a partir de una exterioridad dada; siendo precisamente lo inédito del sujeto la problematización -consciente o inconsciente- de éste estado de cosas. Lo propio ocurre con nuestras percepciones, sentimientos y sensaciones, que de alguna manera están 
socialmente moldeados y sólo encuentran su punto de fuga en el disenso y la confrontación. Empero, estos dispositivos sociales son indispensables para la construcción de la cultura, al tiempo que son una fuente primordial de enajenación propicia para la manipulación ideológica de todo tipo.

La enajenación es una condición de extrañamiento del individuo, en función justamente de una ajenidad exteriormente impuesta, que provoca que el sujeto no se reconozca ni reconozca su participación en la construcción de la materialidad social, siendo este un terreno fértil para la emergencia de las ideologías. De manera tal, que los procesos sociales son vistos como exterioridad, como, algo dado, incólume y estático, que se erige como una realidad invariable, o en el mejor de los casos, mutable sólo a partir de los márgenes de libertad impuestos por el propio sistema, de lo cual, se alimentan las ideologías.

La estructura y naturaleza del poder pasan desapercibidas en la vida social, devienen como un habitus (Bourdieu, 2000) al margen de la consciencia. Tal y como lo propuso Freud (1901/1996), la manifestación de lo inconsciente acaece en la cotidianidad y permea los diversos órdenes de la vida, a lo cual, no escapa por supuesto, la ideología. El propósito último de toda ideología es "posicionarse" en la conciencia y la voluntad del sujeto y con ello contar con su apoyo en función de determinadas ideas e intereses, a partir de un proceso de ocultación que consiste en que los individuos asuman como propio, consciente e inconscientemente, el interés ajeno.

La capacidad de elección del sujeto tiene como lindero las condiciones sociales establecidas que imponen determinados marcos referenciales y las correspondientes prácticas sociales, sean estas oficiales o contestatarias, de manera tal que las respuestas se encontrarán siempre en el conjunto de las posibilidades históricamente dadas. El margen de acción y decisión del sujeto, se encuentra por tanto supeditado a las condiciones concretas de existencia, razón por la cual, las elecciones están predeterminadas y son de cierta manera previas al sujeto que las asume; la libertad de decisión, es siempre relativa.

La efectividad del control ideológico consiste precisamente en hacer creer/sentir que el sometimiento a los mandatos y dictados de la ideología es voluntario y que siempre existen otras alternativas más o menos deseables. Las argumentaciones y razones son una piadosa 
mentira para ocultar el hecho de que la ideología flanquea y controla, de manera casi omnímoda, todas las aristas de la vida societaria. La otredad impone la aceptación normativa que es el tributo que paga el sujeto por su adscripción a la cultura; su desafío implica el escarnio, el ostracismo e incluso la muerte.

El sujeto requiere unos grados de libertad, siempre impuestos, para tener la fantasía de que es fuente de sus decisiones. La argumentación y razonamientos con que justificamos nuestras elecciones, también nos son dadas, aunque las asumamos como sus artífices. A pesar de ello, el sujeto es más que obediencia ciega, siempre tiene la posibilidad de discernir más allá del discurso ideológico y de concebir la trama e intereses que se ocultan tras su invocación, y formular de esta manera, nuevos contenidos ideológicos. Sin embargo, generalmente basta la simple enunciación de la ley para que ésta surta sus efectos, de manera tal, que se cumple aquello que: lo que se enuncia existe.

Las ideologías (políticas, religiosas o científicas) devienen como entelequias productoras de sentido que organizan al mundo y a la vida, brindando un principio de orden y una percepción de predictibilidad fundamentales para orientar el acontecer humano, de aquí su importancia y necesidad que va más allá de sus propios principios y enunciados.

Las ideologías, como representaciones simbólicas del mundo y de la vida brindan una red de certidumbres que posibilitan el funcionamiento social de los individuos y de los sistemas también, al tenor de una supuesta convención y consenso sociales. Dicha convención es solo nominal, lo cual se pone de manifiesto cuando dos sujetos que suscriben una determinada ideología profundizan acerca de su mutua convicción, rápidamente surgen matices y diferencias que nos indican con claridad, que el consenso inicial era tan sólo aparente y relativo.

La ideología construye las subjetividades en función de la asignación y designación del sujeto, a partir de ciertos lugares socialmente establecidos que le definen como portador de determinados rasgos y características sociales, que le hacen reconocible como miembro de un género, etnia, nacionalidad o clase social, entre otros. La adscripción a determinada confesión religiosa o a cualquier otra ideología que se profese, establece modalidades de 
comportamiento y formas de proceder particulares que el sujeto asume como suyas, esto es, como su singular forma de ser.

Con la caída del amo el sujeto queda huérfano de tutelaje, amparado a su propio arbitrio. A partir de este punto se refugia en la libre elección, como posibilidad ideológica que brinda el sistema de manera per-formativa. Tal y como se indicó anteriormente, ideológicamente se hace creer al sujeto que es el artífice de sus propias decisiones, sin poder asumir que sus pensamientos y acciones están predeterminados, aunque siempre existe la posibilidad de una expresión y aportación inéditas al contexto histórico-social, lo cual confirma al sujeto como tal.

El sujeto es sujeto de la historia, de su historia inédita y de la historia que le relaciona con sus congéneres y con el universo social donde habita, en un sentido diacrónico y sincrónico constructor de cultura, sociedad e identidad. La historia es origen y memoria colectiva, al tiempo que experiencia compartida y destino común. La historia es también referencia, contexto y cotidianidad que se presentifica en la materialidad social que acontece vivir y de esta manera, la evolución de las ideologías y del pensamiento en general, se inscriben en la continuidad y disruptividad de la historia.

El sujeto, como sujeto de la historia, no puede ser entendido simplemente como un producto o resultado, debe ser concebido a partir de una relación de sentido -cuando menos dialéctica- suscitada en un campo de tensiones cuya dinámica se mueve entre los límites estructurales históricamente dados y las posibilidades inéditas de su transgresión (individual y colectiva); interjuego que construye la vida social y constituye a los individuos que la conforman. La ideología, es un artefacto que se imbrica entre el sujeto y la materialidad social bajo la forma de mediación discursiva, que permite la aprensión simbólica y la "comprensión" del mundo y de la vida.

Por otra parte, es necesario tener en cuenta que el sujeto es más que las vivencias y modos particulares de apropiación subjetiva del contexto histórico-social, más bien se caracteriza por exceder los determinismos histórico-culturales e ideológicos, a partir de la manifestación y aportación inéditas a la estructura social, aun cuando ésta se manifieste en los términos culturales establecidos. Esta contribución inédita conmueve, de alguna manera, 
la estructura social provocando su desplazamiento y transformación. Es justamente esta impronta, esta novedad evanescente lo que caracteriza al sujeto como tal (Žižek, 2011), siendo su sello distintivo y particular, su huella y aporte al universo social.

Al sujeto de la historia se contrapone el sujeto del inconsciente, el inconsciente concebido como un acontecimiento social (Lorenzer, 1986) que va más allá de lo proscrito social y culturalmente, y que obedece al (des)orden de lo novedoso que irrumpe y trastoca la realidad simbólicamente constituida. Es un lugar-momento-condición donde se manifiesta la subjetividad más allá de las convenciones y dictados sociales, bajo la modalidad de un deseo in-nombrado que moviliza y aporta a la construcción de la estructura societal en función de su realización, ya sea de manera sublimada o francamente transgresora; es el punto de confluencia del individuo y la cultura. El sujeto es lo novedoso en la estructura social en tanto discurre entre las matrices de sentido, re-significando y re-simbolizando, creando de ésta manera nuevas discursividades que impactan y construyen nuevas ideologías. Lo subjetivo se cristaliza a partir la originalidad que el individuo "aporta" a la constelación social, resultado de una carencia y de una ausencia ontológicas que la estructura social no puede obturar.

Lo inconsciente, es una oscura zona que enuncia la ruptura de la dimensión racional, es el par antitético del orden societal (Huson, 2010) y la razón de su existencia desde una perspectiva psicoanalítica. No se trata de un nuevo discurso, ni de un discurso alternativo, mucho menos del establecimiento de una nueva ideología, que necesariamente se inscribirá dentro de los márgenes que dictan los sistemas imperantes, incluso a manera de antítesis. Tampoco tiene que ver con el esclarecimiento de las condiciones de enajenación impuestas. Su contenido no se tramita a partir de la conciencia ni de la palabra, es el anverso, el otro sentido, que abre siempre una nueva perspectiva. Las ideologías como tales, se nutren también del núcleo de lo inconsciente.

Los procesos de subjetivación se erigen en última instancia en función de la posición que asume el sujeto frente a la falta, de lo cual derivarán sus particulares formas de ser, de relacionarse y de vincularse con los otros y con el orden social. Esta falta, en tanto discontinuidad abierta, es lo que hace que en el sujeto se produzca lo inédito y por su mediación provoque el cambio de sí mismo y de la realidad que habita; éste es el aporte 
individual a la construcción colectiva de la organización social. Como hecho performativo se inscribe en la estructura social, al tiempo que la construye y transforma, de manera tal que el trasciende los determinismos sociales y se posiciona como individuo, esto es, como semejante pero diferente a los demás, en función de dicha aportación inédita.

La otredad, como orden simbólico permea los intercambios sociales entre las subjetividades, perfilando sus características y posibilitando cierta inteligibilidad a partir del consenso comunicacional y de un marco societal regulatorio. Sin embargo, a pesar de los condicionamientos sociales, las relaciones inter-subjetivas son ante todo relaciones fantaseadas que se proponen para la interacción social; ellas no parten de la demanda del otro sino más bien de una percepción especular acerca de lo que, subjetivamente, se concibe como la demanda del otro sin que necesariamente se pueda dar cuenta de ésta. El otro, esa instancia a quien va dirigida la intención comunicacional, parte a su vez de la propia percepción fantaseada del deseo de su interlocutor, y le aqueja también la misma imposibilidad ontológica de dar cuenta de manera fidedigna de la demanda de éste (Martínez, 2014). La comunicación es, en última instancia, una acción fallida. De esta manera, los decálogos políticos e ideológicos que convocan a la feligresía tienen múltiples motivos que van más allá de sus principios y enunciados, yendo incluso más allá de las razones enarboladas por los propios sujetos.

El sujeto como tal emerge en el espacio de la estructura social a título de una demanda que sobrepasa los marcos estructurales, pudiendo forzarlos incluso más allá de sus límites. Por esta vía, la estructura se moviliza y cambia a partir de un proceso de re-significación y de re-simbolización, que da por resultado nuevas semánticas e intelecciones, las cuales se traducirán en nuevos discursos e ideologías que impactarán, necesariamente, al horizonte social.

El sujeto es la fisura en la estructura social (Laclau, 2010), su punto de quiebre y discontinuidad; es el enigma y la incertidumbre, lo impredecible en el orden social. Lo que caracteriza al sujeto es ser sujeto de la falta, entendida ésta última como una ausencia en torno a la cual se constituye como sujeto del deseo, deseo que se convierte en motor de su incesante y pródiga búsqueda constructora de historia y de humanidad. 
Žižek (2010) nos dice que la ideología es correlativa a la fisura estructural, porque ahí donde la estructura agota su tiranía simbólica y prescriptiva, emerge el sujeto del deseo y se asoman otras realidades imaginadas que desafiarán y provocarán nuevas consideraciones ideológicas, éticas y estéticas.

Lo Real lacaniano es concebido como aquel núcleo duro y puro que se resiste a la simbolización y a la dialectización, ubicado al margen de la estructura social pero siempre con consecuencias en ésta, en el orden simbólico y en la subjetividad (Žižek, 2012). La fisura estructural, por su lado, es entendida como aquel espacio vacuo, carente de contenido y de estructura (Martínez, 2016). Cabe aquí preguntarse acerca del tipo de relación existente entre Lo real y la fisura en la estructura. Esta pregunta no puede ser respondida del todo, empero, podemos decir que Lo real habita en la fisura estructural que lo contiene, aunque no lo determina al mantener éste su condición de posibilidad siempre aleatoria, digamos que sólo se le puede pesquisar, hasta cierto punto, en sus efectos y en sus consecuencias reales.

Lo real es incorpóreo, inestable e inaprensible. La única manifestación constatable de su presencia consiste en la alteración del orden simbólico (Žižek, 2012). Es un instante donde se rasga la estructura, lo cual presupone, precisamente, la existencia de una cierta estructura que contiene la oquedad a partir de un hipotético borde; la fisura estructural más allá de la estructura y de su tiranía simbólica, es el lugar donde reside lo real. Sin el contenido que supone la estructura, no hay ausencia posible. De lo anterior, se desprende que lo real es el resultado de la vacuidad en el espacio simbólico, aquello que la estructura circunda pero no penetra, abierto al acontecimiento donde el sujeto se encuentra consigo mismo a manera de una primicia, de una novedad en el concierto estructural.

La falta primordial que define las relaciones inter-subjetivas, caracteriza al orden social e impele al sujeto a marchar en pos de una demanda imposible de satisfacer. Dicha exigencia impone al sistema social y a sus aparatos ideológicos trascender los propios límites, ampliando y re-definiendo sus horizontes en un movimiento perpetuo, sin alcanzar jamás la armonía -ni la plenitud-, siempre, en pos de otro horizonte por conquistar. De ésta manera, ésta carencia innominada trastoca a la subjetividad y a la organización social, construyendo nuevas realidades, nuevas subjetividades y nuevas demandas. 
Oेмив LU Wimblu, Rev. Estud. Esc. de Psicología UCR, 13(2) 2018 (Julio-Diciembre): 91-112 /ISSN: 1659-2107

Las ideologías nacen como grandes proyectos utópicos que se agotan en su realización, sin llegar nunca a cumplir a cabalidad su cometido. El sujeto quedará siempre en falta, de manera tal que emprenderá la marcha hacia nuevos horizontes imposibles y creará, a su vez, nuevas ideologías irrealizables. La ideología brinda la posibilidad fantaseada de un cumplimiento de deseo al cual se adscriben los sujetos. Su cometido final apunta a alcanzar una condición en la que desaparece la falta y en última instancia a conjurar la muerte.

Resumiendo, las ideologías como las utopías son irrealizables, aunque necesarias para brindar una orientación y un sentido al quehacer social e individual, al tiempo que permiten conjugar voluntades en pos de un anhelo compartido, aunque no sea necesariamente el mismo para cada quien. Los esfuerzos, fallidos sólo en parte, por consumar los derroteros y propósitos ideológicos, impulsan a los dominios societales a moverse más allá de sus fronteras, al principio como una alteridad extraña, que sólo con el paso del tiempo se asimila e integra para constituirse en una realidad que termina siendo naturalizada, cumpliendo así su cometido en el perpetuo devenir.

\section{Ideología, saber y poder}

El binomio poder/saber se constituye, como nunca antes en la historia, en una poderosa e indisoluble amalgama, a tal punto, que el gobierno sobre las cosas y personas es una tarea imposible sin el auxilio de la información, la ciencia y la tecnología. El binomio poder/saber se convierte de ésta manera en saber/poder. Empero, más allá de la mediación e instrumentación que se asuma, el objetivo último de toda ideología sigue siendo el control de la conciencia, de la voluntad y de las acciones de los individuos.

A partir de la contemporaneidad, existe una mirada crítica al binomio saber/poder y a las formas de producción y organización del conocimiento, no sólo en el sentido del establecimiento de nuevos discernimientos, opuestos formalmente a los saberes instituidos, sino también de las modalidades de transmisión y de las fuentes de conocimiento como tales (Badiou, 2013). En este contexto, se aboga por una ruptura de la concepción de hegemonía del saber centrada en la figura del maestro o el experto, se horizontaliza y democratiza el ejercicio del proceso de enseñanza-aprendizaje y se relativiza la verdad. De igual manera, las 
ideologías tienden a perder su carácter absolutista y se comienzan a imponer las ideologías de la tolerancia, la libre oferta de saberes y la inclusión, sólo por mencionar algunas. La Internet y las redes sociales han contribuido a la ruptura del monopolio del conocimiento y al libre flujo de la información logrando, hasta cierto punto, democratizar el acceso al conocimiento y a la posibilidad de la producción y transmisión del pensamiento, al margen de los burocráticos y elitistas medios de difusión tradicionales.

Las "verdades", concebidas con pretensiones de ser absolutas, están destinadas a prevalecer sobre otras "verdades absolutas", no pocas veces antagónicas, todo ello, como parte de la libre concurrencia en el mercado de ideologías, las cuales suelen apoyarse en supuestos de partida apriorísticos e indemostrables y en esa condición exigen actos de fe que hacen posible la construcción de una "estructura de certidumbres", las cuales se revelan como entidades de "pies de barro" cuando se develan los mecanismos que les dan origen.

La verdad, así concebida, se basta a sí misma y se define y re-define en sus propios términos de manera tautológica; su sola enunciación evoca certeza, aunque no se trate de una convicción racionalmente sustentada. La separación que solemos hacer entre la verdad y la falsedad tiene que ver con nuestras creencias y deseos, no pocas veces contrarios a las evidencias, las cuales con frecuencia son falseadas para hacerlas coincidir con la matriz de convicciones que ostentamos, siendo la verdad algo profundamente subjetivo3.

La realidad percibida, es tan sólo la presunción que el sujeto hace de esta, presunción en el marco de la cual actúa. La realidad objetiva es una forma de enunciar una ideología en donde se parapeta la ciencia en su vana pretensión de verdad, al obviar y negar el papel de la ideología como constructora de realidades sociales y científicas. La verdad, cuya única forma

3 El escritor Haruki Murakami (2014:250) en su novela "Al sur de la frontera, al oeste del sol" describe de manera clara esta dinámica en las reflexiones de uno de sus personajes: Hay una realidad que demuestra la verdad de un hecho. Porque nuestra memoria y nuestros sentidos son demasiado inseguros, demasiado parciales. Incluso podemos afirmar que muchas veces es imposible discernir hasta qué punto un hecho que creemos percibir es real y a partir de qué punto solo creemos que lo es. Así que, para preservar la realidad como tal, necesitamos otra realidad - una realidad colindante- que la relativice. Pero, a su vez, esta realidad colindante necesita una base para relativizarse a sí misma. Es decir, que hay otra realidad colindante que demuestra, a su vez, que esta es real. Y esta cadena se extiende indefinidamente en nuestra conciencia y, en un cierto sentido, puede afirmarse que es a través de esta sucesión, a través de la conservación de esta cadena, como adquirimos conciencia de nuestra existencia misma. Pero si esta cadena, casualmente, se rompe, quedamos desconcertados. ¿La realidad está del otro lado del eslabón roto? ¿Está a este lado? 
de expresión posible es en términos simbólicos -sean estos conceptuales o matemáticos-, no guarda una correspondencia unívoca ni isomórfica con la realidad fáctica, al colarse la ideología en su formulación y concepción. Toda comprensión social y científica está atravesada, indefectiblemente por la ideología.

La ideología en su condición de falsa apariencia, es una realidad en la cual subyace una verdad enunciada (independientemente de su certeza), a partir de lo cual se organiza y estructura el orden simbólico, no menos cierta en sus consecuencias que aquello que tergiversa y oculta. Es imposible concebir la organización social y su funcionamiento, sin el andamiaje ideológico que la anima y sustenta.

Cabe preguntarse entonces, ¿Qué es lo que oculta la ideología? La respuesta de Žižek (2012) al respecto es contundente: nada. Lo característico de la subjetividad es el posicionamiento inédito del sujeto frente a este espacio infranqueable que no existe; es tan sólo la propia ilusión lo que encontramos en dicho espacio "vacío", que se alimenta, precisamente, de las atribuciones y expectativas subjetivas. Es la propia falencia del sujeto y su materialización en un deseo inerme y sin objeto lo que subsiste tras esta nada inescrutable, lo que prevalece, a fin de cuentas, es el sujeto del deseo. Llegando a este punto surge la pregunta: ¿a qué conduce esta falacia y esta ausencia y por qué se mantiene?; sin mayor retórica podemos responder, de manera clara, que se mantiene porque esta ilusión es imprescindible para el funcionamiento del sistema, esta promesa, siempre incumplida, es el motivo por el cual se movilizan órdenes sociales e individuos con la secreta esperanza de colmar un anhelo imposible, lo cual, tiene por efecto el indispensable dinamismo de la estructura social.

Las ideologías se constituyen a partir de esta nada generativa, de este espacio libre de estructura y contenido, donde es posible ir más allá del rigor de la realidad. De esta manera, la nada se presentifica y se materializa en algo, acaso un difuso y efímero deseo que usurpa brevemente este “espacio vacío" que no logra colmar. Para Žižek (2012), el sujeto es la imposibilidad de su propia representación significante, que convierte la falta del significante en el significante de la falta. 
О人лмв LU Wimblu, Rev. Estud. Esc. de Psicología UCR, 13(2) 2018 (Julio-Diciembre): 91-112 /ISSN: 1659-2107

Según Žižek (2010), el sujeto del supuesto saber lacaniano tiene necesariamente su contraparte lógica en el sujeto supuesto creer que es quien autoriza, legitima e instituye en definitiva la pretendida sabiduría del primero; lo cual, no es otra cosa más que una construcción espectral y auto referencial del sujeto frente a la propia ignorancia y a la necesidad de una respuesta, de esta manera, el sujeto formula una pregunta que nunca será respondida. Esta pregunta no va dirigida a nadie en particular, sin que esto signifique que sea un recurso retórico, ya que tanto la pregunta como la demanda de respuesta son importantes y decisivas para el sujeto. La pregunta va dirigida a un oráculo imaginario cuya única característica consiste en que no escucha, existe en tanto el sujeto cree sinceramente en su presunta existencia y en que tiene la respuesta. Cuando el oráculo habla, el sujeto escucha su propia voz, ajena y extraña, no logra reconocerla y la asume fuera de sí; pero en realidad, lo que escucha son sus propios designios y deseos. Los oráculos, son ideologías múltiples y diversas, cada una con su propia verdad, frente a los cuales los sujetos plantean sus incertidumbres. Renunciar al oráculo, significa vivir con la certeza de la propia ignorancia, la falencia, la finitud y la soledad.

\section{Ideología como dispositivo que anuncia la realización de deseo}

El gran Otro, como orden establecido, no existe al margen de las dinámicas sociales, tampoco es una intelección que organiza y determina la vida social. Por el contrario, se corporiza en los actos y acciones individuales y colectivas, en los intercambios íntersubjetivos y en las estructuras sociales donde habita y que a la vez contribuye a constituir. Es más bien un proceso que un producto o resultado, siempre mutante, diverso, múltiple, etéreo, inalcanzable y omnipresente, cuyo control en definitiva escapa al manejo y al ejercicio de las voluntades, sean estas individuales o colectivas. Su existencia se debe al conjunto de los intereses y contradicciones sociales que, más allá de cualquier determinismo histórico, sólo obedece a su propia dialéctica.

El poder simbólico es más que una amenaza con consecuencias, es ante todo una virtualidad a la que se le teme en función de la posibilidad de sufrir ataques reales o fantaseados; temido y admirado suele ser objeto de identificación, de lo cual deriva en un 
sometimiento voluntario, cumpliéndose así la máxima gramsciana de hegemonía más consenso. En tal sentido, la vinculación con el poder posee un carácter ambivalente de atracción/repulsión que genera pasiones, odios, temores y amores.

La posibilidad de burlar al amo y escapar a su control, resarciendo de esta manera, al menos en parte algún supuesto daño infligido, ata al individuo a la dinámica del poder y lo coloca en el oblicuo lugar de la sujeción. Por esta vía nunca se alcanzará, si eso fuera posible, la anhelada libertad. En todo caso, el sometimiento a la autoridad brinda un marco de certidumbre y seguridad que es el pago por el sometimiento (consciente e inconsciente) y por los servicios prestados al poder. La autoridad del amo, se encuentra sustentada en el deseo de los otros al asumir éste la realización (imposible) del deseo de los otros. En tal sentido, el goce del Otro se convierte en la fuente del propio goce.

El discernimiento entre realidad y fantasía carece de linderos establecidos que posibiliten, sin ambigüedades, su reconocimiento. El propio Freud fue inicialmente "víctima" de sus pacientes histéricas, a quienes les creyó sin ningún tipo de cortapisa sus "recuerdos" de incesto. Posteriormente, comprendió que en algunos casos el hecho había acaecido, en tanto que en otros era resultado de las fantasías incestuosas de sus pacientes; y que no era posible discernir fantasía de realidad.

El deseo, no existe en forma pura sino que aparece ataviado con el ropaje de la fantasía, a partir de lo cual se define el objeto y sus contornos. Para Žižek (2010), el núcleo del goce es a-histórico, no así el objeto del deseo y sus manifestaciones, que acaecen bajo determinadas coordenadas socio-históricas que trasudan a la cotidianidad; es cuestión de mirar más allá de la veladura lo que se presenta ante nuestros ojos. La ideología deviene a su vez como objeto de deseo.

La vacuidad, que indefectiblemente nos remite a una falta, no es la ausencia de un objeto determinado, sea este material o fantaseado; se trata más bien de la imposibilidad de satisfacer un deseo que sobre el objeto recae, pero que lo excede ampliamente ya que no logra una satisfacción plena. El deseo se encarna en el objeto como posibilidad de vehiculización y expresión, pero nunca es lo que realmente se desea; en otras palabras, ateniéndonos a la doctrina freudiana, el objeto es revestido libidinalmente y deja de ser lo que realmente es, 
para constituirse en objeto del deseo, a partir de lo cual se le inviste de cualidades y se le otorgan réditos que claramente lo trascienden. En este punto es necesario preguntarse: ¿Cuál es el verdadero objeto del deseo? El psicoanálisis responderá, desde una perspectiva psicogenética, que es el anhelo de la plenitud perdida en el inicio de la vida, que tan sólo nos es dado experimentar momentáneamente.

Más allá de la fantasía y sus formas, encontramos un deseo que trasciende las coordenadas espacio-temporales, ajeno a la materialidad concreta, perenne y al acecho de un objeto que nunca es su propósito, pero que se trasviste con él y en él, siempre inalcanzable e imposible. El objeto del deseo transmuta y cambia, sólo el deseo como tal, indescriptible en su infinita soledad, persiste informe suspendido en el tiempo. La ideología, viene a ser uno de los tantos ropajes del deseo. El deseo denuncia la in-completud del orden simbólico, incompletud que no es inherente a éste, sino, correlativo a una demanda imposible que adquiere múltiples formas; el deseo es, en extremo, un deseo sin objeto, pero que paradójicamente requiere de un objeto como posibilidad de ser y como vehículo de su expresión. La fantasía cumple una función de intermediación entre el deseo como tal y la realidad simbólica, en un intento de obturar las “ausencias” del orden societario (Žižek, 2010).

La ideología, allende su connotación política y su adscripción histórica a los intereses de clase, contiene elementos que se inscriben en el orden de la fantasía y el deseo, sin los cuales, no podría cumplir su función. La ideología en su condición de utopía es la depositaria de las fantasías sociales e individuales que la constituyen, de manera tal que se entreveran los anhelos y las voluntades en pos de un mítico propósito común, donde cada quien concurre con su propio deseo, semejante pero diferente al del prójimo. De esta manera, se establecen redes de referencias a partir de un denominador común, que concita los deseos bajo el auspicio de ideales y principios compartidos donde los individuos se sienten representados. La vulnerabilidad de los discursos ideológicos consiste, precisamente, en que las atribuciones e interpretaciones que se realizan de sus enunciados y propósitos están lejos de ser unívocos y universales; en parte, porque se filtran intereses y necesidades sociales, políticas y personales de muy diversa índole, y en parte porque en su materialización concreta, esto es, en su puesta en práctica, se desdora la perfección ideal de su concepción, a partir de las desavenencias y tropiezos que la terca realidad impone. 
El deseo como tal, no sólo se conjuga en el más allá de las estructuras sociales, sino también en los dominios societarios, a partir de la existencia de utopías sociales, políticas y religiosas que se materializan bajo la forma de discursividades (dominantes o contestatarias), que en todo caso, reconocen e incluyen los anhelos de todos aquellos que se acogen a su fuero ideológico, condición sin la cual no podrían ser operativas (Žižek, 2011). La fidelidad y legitimidad de dicha representación, es sin duda cuestionable, así como los intereses subrepticios que se ocultan detrás de ésta ya que, antes de dar respuesta a las demandas planteadas, de lo que se trata es de mantener vivo el deseo y la esperanza de su realización, siempre dentro del marco del universo ideológico de referencia.

Las ideologías se alimentan de las necesidades humanas, a las cuales nunca darán cabal respuesta, ya sea porque lo solicitado y prometido excede las posibilidades históricas, sociales y políticas para su realización, o porque poderosos intereses ocultos tras reivindicaciones justas terminan conculcándolas, o porque lo que se demanda no es realmente lo que se desea y consecuentemente siempre existirá una insatisfacción. En todo caso, el deseo es siempre correlativo a la existencia de todos los sistemas ideológicos.

Siguiendo a Freud (1923), diremos que, siendo el inconsciente libre del principio de realidad, de toda contradicción y temporalidad, es ajeno a la finitud del sujeto y por tanto tendiente a la inmortalidad, lo cual va a engarzar con las promesas de trascendencia que, como valor supremo ostentan todos los sistemas religiosos. Análogamente, las ideologías brindan un sentido de trascendencia que nos inmortalizará en la obra humana a la cual pertenecemos y de la cual participamos, proyectándonos más allá de nuestra existencia física, al punto que, eventualmente, podríamos estar dispuestos a ofrendar nuestra propia vida por una causa, en función de redimir a las generaciones futuras, justificando de esta manera nuestra existencia. Las obras que legamos conculcan el anonimato de la muerte y nos sobrevivirán para nuestra propia honra y gloria. Dicho legado, cualquiera que sea, contribuirá al resarcimiento narcisístico, al engrandecimiento yoico y al sentimiento de trascendencia, a la vez que brindará un sentido y una orientación vital a nuestros pensamientos y acciones.

La ideología, concebida como fantasía optativa, da pie al cumplimiento de deseos o al menos a la promesa de que ello ocurra. La ideología es un norte que encauza las acciones 
humanas en pos de horizontes utópicos a manera de sueños diurnos, siempre con consecuencias, que contribuyen a prefigurar las realidades sociales y subjetivas. Es precisamente este núcleo fantaseado -que promete el cumplimiento de deseos- y no el decálogo político, lo que hace que los individuos se adscriban a determinadas ideologías y no a otras. Las “decisiones", en última instancia, no se encuentran sustentadas principalmente en una lógica argumental, sino en los anhelos y deseos personales. Cada quien tiende con sus propias necesidades y propósitos al abrazo de ciertas ideologías, sean estas filosóficas, políticas o religiosas. Todas las ideologías, si quieren ser funcionales y sobrevivir en el mercado ideológico, deberán mostrar un núcleo de goce (Žižek, 2010).

Empero, a pesar de todos los esfuerzos, al pertenecer la ideología al orden de lo simbólico, no pasa de ser un vano intento de apalabrar un deseo inescrutable, frente a la imposibilidad de la estructura social; siendo la realización fantaseada de un deseo y un placer anticipatorio y supletorio, a manera de compensación, así como la promesa (imposible) de su realización (Freud, 1915/2012).

La ideología pertenece al espectro de lo posible/imposible, siendo su realización incierta, aunque sus consecuencias son siempre reales; su pertenencia al mundo de las ideas marca indefectiblemente una discontinuidad con su realización, ya que las cosas nunca son como se conciben, estando determinadas por una falta y un exceso que distorsionan cualquier propósito ideal.

La burocratización de la maldad se asume como parte de una rutina más que es necesario cumplir, independientemente del horror y el dolor que puedan provocar a los otros; un mal necesario que reconfigura coyunturalmente consideraciones éticas y morales. En la lógica fascista así se cumple con la patria y el destino: las acciones se asumen con obediencia mecánica incuestionable al deseo del Otro, quedando a fin de cuentas la satisfacción del deber cumplido, que deviene como un goce perverso suplementario y una fuente de resarcimiento narcisista.

En general las más horrendas violaciones a los derechos humanos y los crímenes de lesa humanidad se han cometido en nombre de la justicia y el progreso social con la complicidad activa y pasiva de la mayoría moral. Esta situación conlleva a la bancarrota 
ideológica y a negar los preceptos que sustentan las ideologías, al tiempo que destruyen las fantasías que las sostienen, salvo cuando estas están imbuidas del principio de destrucción y de muerte. La degradación ideológica suele ser el paraíso de los perversos; la maldad, no pocas veces, se cobija bajo el manto de la ley, la obediencia y el bien común.

Aquel contenido ideológico excluido, rechazado o proscrito, adquiere en un determinado momento el carácter erótico de la cosa prohibida, suscitando de esta manera un deseo ilegítimo que trasciende la ideología, pero que se origina en ésta. El perverso no sólo anhela el objeto prohibido en tanto el objeto último de su deseo es ser él la ley (Žižek, 2010) y usurpar de esta manera el lugar del amo, siendo así su propio amo y el amo de los demás. Imponer la ley, la propia verdad y la voluntad, es la secreta promesa de todo sistema ideológico.

Retomando a Žižek (2010) diremos, que la transgresión necesita un límite para afirmarse. La transgresión contribuye a definir los contornos y perfiles de la ley, la prohibición tiene como correlato y presupone su desacato, siendo este su reverso y su razón de ser. Si la transgresión deja de ser tal, la ley pierde sentido y deja de existir. Siempre se invoca el espíritu de la ley, cualquiera que éste sea, ya que su aplicación a ultranza se vuelve perversa (Žižek, 2010), nunca mejor dicho que la excepción confirma la regla. Sin estos márgenes el poder se vuelve inviable, incapaz de mostrar su supuesta "benignidad" y por esta vía se pierde la posibilidad de ganar legitimidad. La coacción pura y dura a la larga es inversamente proporcional a la viabilidad y existencia de cualquier régimen social.

La transgresión prodiga un placer que no deriva necesariamente del acceso al objeto prohibido, sino más bien en la transgresión misma. En algunas ocasiones, la transgresión se justifica en el propio discurso ideológico, dentro de cierta banalidad del mal. Como contrapartida, para Žižek (2011) la dominación posee a la vez una dimensión libidinal no sólo para quienes detentan y disfrutan de las mieles del poder, sino también para aquellos que, estando bajo la subyugación, se someten de manera voluntaria sin oponer resistencia alguna al dominio impuesto. Lo anterior, suele ocurrir en función de una suerte de erotización derivada de la propia condición de sometimiento, a manera de un goce sado-masoquista, concebido, en éste caso, desde el lugar de la sujeción y como aliado al poder. 
Oेмив LU Wimblu, Rev. Estud. Esc. de Psicología UCR, 13(2) 2018 (Julio-Diciembre): 91-112 /ISSN: 1659-2107

El amo, para serlo, cifra su autoridad en la asunción del deseo del otro y en la promesa, siempre incumplida, de su realización. La autoridad del amo es una autoridad especular construida a imagen y semejanza del deseo del otro. En general, el uso de la coerción como forma de dominación, es inversamente proporcional a la catectización de la figura del amo.

\section{Conclusión}

La ideología, es más que un marco de referencia social que organiza el mundo y la vida al tiempo que norma y media las relaciones entre los individuos; construye subjetividades que a su vez conforman la historia y sus vicisitudes. Más allá de sus servicios al poder, a partir del imperio de una racionalidad justificadora, la ideología impone formas de pensar, sentir y actuar que son asumidas de manera personal, lo que generalmente escapa o se hace opaco al escrutinio crítico y a la consciencia, al tiempo que facilita hacer pasar el interés ajeno como propio. Precisamente, la eficacia del control ideológico es correlativa a la falta de consciencia del mismo. En la modernidad tardía, con la caída del amo, el sujeto sufre una orfandad de tutelaje, imponiéndose la libre elección ideológica, a veces contradictoria entre sí, aunque siempre dentro de la lógica de la reproducción del sistema imperante.

La ideología, llena necesidades de diversa índole bajo la modalidad de una expectativa de satisfacción que nunca se cumple pero que siempre se espera. Sin embargo, no todos los anhelos y deseos se tramitan a partir del mercado de ideologías existentes, más allá de las convenciones y dictados sociales persiste el deseo como sustrato reacio a someterse a los designios ideológicos de cualquier naturaleza, y en virtud de ello, su simple demanda pone a prueba constantemente a la estructura social. Es producto de esta demanda imposible de atender donde emerge la impronta del sujeto y su inscripción como tal en la realidad social, esto es, como semejante pero diferente a la vez.

El llamado de las ideologías, tiene una recepción fantaseada en pos de la cual cada quien concurre con su propio deseo que deposita en el discurso ideológico al tiempo que lo trasciende, forzando de esta manera los límites del mismo y propiciando su transformación. La ideología, encarnada en el sujeto deviene como una suerte de realización fantaseada de deseo, al cual nunca se le da respuesta. En primer lugar, porque la representación consciente 
de lo que se anhela es siempre una formación sustitutiva, una especie de revestimiento o apariencia, una expresión metafórica que no necesariamente guarda una relación isomórfica con lo que se desea (Freud, 1915) y, en segundo lugar, porque la ideología en su condición de utopía es un horizonte efímero que nunca da cabal cumplimiento a sus propios propósitos y enunciados. En todo caso, el encuentro de estas dos dimensiones, y la siempre insatisfecha condición de las demandas fantaseadas, dibujarán nuevos horizontes y nuevas utopías.

Ahí, donde se quiebran la estructura y su tiranía simbólica, donde el sujeto se encuentra a sí mismo en su condición de impronta y acontecimiento inédito de la totalidad estructural, es donde emergen las ideologías en tanto proveedoras de satisfacciones sustitutivas a una demanda imposible que, no obstante, marcará derroteros y un principio de orientación que alineará sujetos y convocará voluntades. Las ideologías, sean estas religiosas, políticas o científicas, proveerán certezas a partir de las cuales se organizarán las estructuras sociales, siendo la mayor de las falacias la objetividad científica y su falsa pretensión de dar cuenta objetiva de la realidad.

Por otra parte, tenemos que el Amo se constituye a imagen y semejanza de los deseos de quienes reconocen su autoridad y derivan beneficios (reales y fantaseados) a partir de su sometimiento consciente e inconsciente. El Amo es ideología, no existe fuera de ésta. El Amo encarna una expectativa y una promesa (individual y colectiva) de realización de deseo, que ata al sujeto indefectiblemente a éste. La adherencia a los mandamientos ideológicos, que aparecen como demandas del Amo, se encuentra en relación directa con la expectativa de cumplimiento de las fantasías optativas sublimatorias que se juegan a nivel de la ideología.

Ese plus de la ideología, eso que está más allá de la retórica y de sus enunciados, queda a cargo del sujeto que demanda un goce y una respuesta que la ideología no provee pero que alimenta y sostiene. La respuesta que obtiene el sujeto a sus demandas y preguntas es una nada y un silencio generativos en donde se encuentra y se escucha así mismo como alguien ajeno y extraño. Tenemos también, que la propia condición de dominación y sujeción crea un goce suplementario de naturaleza sado-masoquista que resarce al sujeto. Si el Amo, que se encuentra al servicio de sus acólitos no provee de alguna manera el resarcimiento libidinal que se le demanda, será desterrado y cambiado por otro. Por último, el desafío al Amo 
OЛпмв Lu Wimblu, Rev. Estud. Esc. de Psicología UCR, 13(2) 2018 (Julio-Diciembre): 91-112 /ISSN: $1659-2107$

adquiere un sentido erótico a partir de la "cosa prohibida", lo que más que liberar al sujeto lo ata indefectiblemente a éste.

\section{Referencias}

Badiou, Alain. (2013). La aventura de la filosofía francesa a partir de 1960. Buenos Aires, Argentina: Eterna Cadencia Editora.

Bosteels, Bruno. (2010). La teoría del sujeto de Alain Badiou: el reinicio del materialismo dialéctico. En: Žižek, S. (ed). Lacan Los Interlocutores Mudos. Madrid, España: Ediciones Akal.

Bourdieu, Pierre. (2000). La dominación masculina. Barcelona, España: Editorial Anagrama.

Freud, Sigmund. (1901/2012). Psicopatología de la vida cotidiana. Obras completas. Tomo 1. Madrid, España: Editorial Nueva Biblioteca.

Freud, Sigmund. (1913/2012). Tótem y Tabú. Obras completas. Tomo 2. Madrid, España: Editorial Nueva Biblioteca.

Freud, Sigmund. (1915/2012). Los instintos y sus destinos. Obras completas. Tomo 2. Madrid, España: Editorial Biblioteca Nueva.

Freud, Sigmund. (1923/2012). El yo y el ello. Obras completas. Tomo 3. Madrid, España: Editorial Biblioteca Nueva.

Hinkelammert, Franz. (1996). El mapa del emperador. Determinismo, caos, sujeto. Recuperado: $\quad$ www.pensamientocritico.info/index.php/libros/libros-de-franzhinkelammert/espanol [Consulta13 ene. 2016].

Huson, Thimoty. (2010). Lacan y los presocráticos. En: Žižek, S. (ed). Lacan Los Interlocutores Mudos. Madrid, España: Ediciones Akal. S.A.

Laclau, Ernesto. (2012). Prefacio. En Žižek, S. El sublime objeto de la ideología. Buenos Aires, Argentina: Siglo Veintiuno Editores.

Lasch, Christopher. (1996). Refugio en un mundo despiadado. Reflexión sobre la familia contemporánea. Barcelona, España: Editorial Gedisa, S.A. 
Lorenzer, Alfred. (1986). Símbolo, interacción y praxis. México DF, México: Siglo XXI.

Mitscherlich, Alexander. (1965). Acusación a la sociedad paternalista. Barcelona, España: Ediciones y Distribuciones Sagitario S.A.

Murakami, Haruki. (2013). Al sur de la frontera, al oeste del sol. México DF, México: Tusquets Editores.

Martínez, Manuel. (2007). Claves para una mayor comprensión entre la subjetividad y la cultura. En S. Baltodano, I. Dobles, V. Leandro, Psicología de la liberación en el contexto neoliberal. (pp. 163-167) San José, Costa Rica: Editorial de la Universidad de Costa Rica.

Martínez, Manuel. (2014). Constitución de la subjetividad. Reflexiones psicogenéticas. San José, Costa Rica: Editorial UCR.

Martínez, Manuel. (2016). El sujeto de la fisura estructural. Consideraciones ontológicas. Revista Reflexiones, 95 (2), 57-67.

Quirce, Carlos. (2014). Reflexiones psicológicas y filosóficas sobre una nación en crisis. San José, Costa Rica: EUNED.

Žižek, Slavoj. (2010). El acoso de las fantasías. Madrid, España: Siglo Veintiuno Editores.

Žižek, Slavoj. (2011). El espinoso sujeto. Buenos Aires, Argentina: Editorial Paidós.

Žižek, Slavoj. (2012). El sublime objeto de la ideología. Buenos Aires, Argentina: Siglo Veintiuno Editores. 